\title{
Overnight hospital stay and/or extended recovery period may allow long-duration oral and maxillofacial surgeries in the operating room of a dental hospital in an outpatient setting: a single-center experience
}

\author{
Filiz Uzumcugil ${ }^{1}$, Aysun Ankay Yilbas' ${ }^{1}$, Basak Akca'1, Demet Basak Ozkaragoz ${ }^{1}$, \\ Selen Adiloğlư², Hıfzı Hakan Tuz ${ }^{2}$, Meral Kanbak ${ }^{1}$ \\ ${ }^{\prime}$ Department of Anesthesiology and Reanimation, Hacettepe University School of Medicine, \\ ${ }^{2}$ Department of Oral and Maxillofacial Surgery, Hacettepe University Faculty of Dentistry, Ankara, Turkey
}

\begin{abstract}
J Korean Assoc Oral Maxillofac Surg 2020;46:125-132)
Objectives: The requirement for overnight hospital stay should be considered preoperatively according to patient-related factors, type of surgery, and anesthetic management plan. In this study, we aimed to define the major factors that influence consideration of overnight hospital stay in patients undergoing oral and maxillofacial (OMF) surgery in an operating room (OR) of a dental hospital in an outpatient setting.

Materials and Methods: The records of patients who underwent oral procedures under general anesthesia between 2014-2017 were reviewed.

Results: A total of 821 patients underwent oral procedures under general anesthesia; 631 of them underwent OMF surgery in the OR of a dental hospital, and 174 of these patients were hospitalized for overnight stay. There was no significant difference in the number of patients with comorbidities between the outpatient and hospitalized patient groups $(P=0.389)$. The duration of surgery was longer in the hospitalized patient group $(105.25 \pm 57.48$ vs $189.62 \pm 82.03$ minutes; $P<0.001$ ). Double-jaw ( $=15 ; 310.00 \pm 54.21$ minutes) and iliac crest grafting surgeries ( $\mathrm{n}=59 ; 211.86 \pm 61.02 \mathrm{minutes})$ had the longest durations. Patients who underwent iliac crest grafting had the highest rates of hospitalization (79\%). The overall recovery period was longer in outpatients ( $119.40 \pm 41.60$ vs $149.83 \pm 52.04 ; P<0.001)$.

Conclusion: Duration of surgery was the main determinant in considering whether a patient required overnight hospital stay. However, patients with an American Society of Anesthesiology physical status score $<3$ may be scheduled for OMF surgery in the OR of a dental hospital in an outpatient setting regardless of duration of surgery if overnight hospital stay is planned or an extended recovery period is provided until patients meet the discharge criteria.
\end{abstract}

Key words: Anesthesia, Inpatients, Oral and maxillofacial surgery, Outpatients

[paper submitted 2019. 2. 14 / revised 2019. 5. 13 / accepted 2019. 5. 15]

\section{Introduction}

Oral and maxillofacial (OMF) surgeries can be performed in office-based settings, outpatient facilities, or hospitals ${ }^{1,2}$. All these facilities, except office-based sites, may involve an overnight stay in a hospital ${ }^{3}$. Patients who have an American

\section{Filiz Uzumcugil}

Department of Anesthesiology and Reanimation, Hacettepe University School of Medicine, Sihhlye, Ankara 06230, Turkey

TEL: +90-3123051260 FAX: +90-3123109600

E-mail: filizuzumcugil@hotmail.com

ORCID: https://orcid.org/0000-0001-9161-3248

(c) This is an open-access article distributed under the terms of the Creative Commons Attribution Non-Commercial License (http://creativecommons.org/ licenses/by-nc/4.0/), which permits unrestricted non-commercial use, distribution, and reproduction in any medium, provided the original work is properly cited. Copyright (C) 2020 The Korean Association of Oral and Maxillofacial Surgeons. All rights reserved.
Society of Anesthesiology (ASA) physical status score $\geq 3$ and/or who are scheduled for a procedure that is performed under general anesthesia for a duration $>90$ minutes are not recommended for day surgeries (outpatient/ambulatory) and should be offered a hospital stay overnight $t^{4}$.

Appropriate patient selection for day surgeries performed in an office or outpatient facility provides a safer approach, but adverse events that require hospitalization may occur after OMF surgeries ${ }^{4-6}$. The rate of unanticipated hospital admissions following ambulatory surgeries was previously reported as $2.67 \%{ }^{5}$. The rate of unanticipated hospital admissions was $0.13 \%$ in patients after dental surgery ${ }^{3}$. Studies that have investigated unexpected hospital admissions after ambulatory surgeries suggest that careful preoperative evaluations be performed to select patients suitable for day surgeries and recommend considering the need for an overnight hospital 
stay to reduce patient morbidity ${ }^{4-6}$. It has also been suggested that lack of availability of an overnight hospital stay had the potential for worse patient outcomes ${ }^{3}$. The decision to schedule an overnight hospital stay prior to surgery may offer a safer approach in OMF surgeries performed at dental hospitals in outpatient settings.

All patients at our hospital who are scheduled for OMF surgeries that will be carried out under general anesthesia must undergo a preoperative evaluation. The anesthesia team performs a triage process to determine whether to send these patients to the operating room (OR) at the dental hospital (outpatient setting) or to the OR in the main hospital (inpatient setting) according to type of surgery, type of anesthetic management required, and patient health. The requirement for an overnight hospital stay in the postoperative period is decided according to patient needs prior to surgery regardless of the location chosen for the procedure.

Our aim was to share our experiences of patients who underwent OMF surgery under general anesthesia with endotracheal intubation in the OR of a dental hospital that also performs procedures in an outpatient setting. The primary goal of our study was to define whether the length of surgery or any particular comorbidities of the patients determined the requirement for an overnight hospital stay.

\section{Materials and Methods}

We obtained approval from the Institutional Ethical Committee (GO17/83-21, 28.02.2017) of Hacettepe University and reviewed the anesthesia records of patients who underwent OMF surgery at Hacettepe University from January 1, 2014 to January 1, 2017.

\section{The facilities in which the oral procedures were performed}

The Dentistry Department in Hacettepe University Hospital contains two ORs and provides the option for an overnight stay but serves only as an outpatient facility for OMF surgeries. According to the needs of the patients and surgeons, the anesthesia team may schedule surgery in the OR of the dental hospital or at the main hospital either with or without overnight hospital stay. All patients with difficult airway or comorbidities referring to an ASA physical status score $\geq 3$, and risks for adverse events (such as malignant hyperthermia) undergo OMF procedures in the OR of the main hospital as inpatients. Healthy patients without any anticipated airway problems are scheduled for surgery in the OR of the dental hospital as outpatients regardless of duration of surgery. The $\mathrm{OR}$ at the Faculty of Dentistry has a dedicated anesthesia team that includes a specialist, two anesthesia nurses, and a nurse for the recovery room. The OR has comprehensive facilities, including an anesthesia working station and recovery rooms for follow-up during the postoperative period. A twostage recovery period is used as follows: 1) an intense observation and monitoring period and 2) a less rigorous period after the patient regains consciousness and recovers from any adverse events. A nurse attends to the patients in a primary recovery area in the first stage, and then the patients are brought to a secondary recovery area where they can be with their responsible parties during the second stage. Patients who require overnight stay in the hospital are transferred to the main hospital within five minutes under the supervision of the attending anesthesiologist via ambulance. All patients must meet the discharge criteria assessed with the modified Aldrete score (MAS) prior to discharge to home or transfer to the main hospital for an overnight stay ${ }^{7}$.

\section{Patients}

Patients who underwent oral procedures under general anesthesia between January 1, 2014 to January 1, 2017 were identified. Preoperative anesthetic evaluation forms, intraoperative anesthesia records, and postoperative nurse follow-up charts and checklists were reviewed. Patients who underwent surgery in the OR of the main hospital with inpatient status and patients who underwent surgery other than OMF procedures in the OR of the dental hospital were excluded from the analyses.

\section{Data collection}

Data on the demographic characteristics, comorbidities, type of surgery, duration of surgery, duration of recovery, time to discharge/transfer, and admission for overnight hospital stay were obtained. Postoperative adverse events and interventions to treat these events were also obtained.

\section{Statistical analysis}

Data were analyzed using the SPSS Statistics (ver. 17.0; SPSS, Chicago, IL, USA). The Kolmogorov-Smirnov test was used to determine whether the continuous numerical variables were close to normal. Descriptive statistics are 
defined using mean \pm standard deviation, median (minimummaximum) for continuous numerical variables, and numbers of patients and percentages ( $\%$ ) for categorical variables. The significance of the relationships between hospital stay and comorbidities and duration of surgery was analyzed using Pearson's chi-square and Mann-Whitney U tests. $P$-values $<0.05$ were accepted as significant.

\section{Results}

This study reviewed 821 patients who underwent oral procedures under general anesthesia with endotracheal intubation between January 1, 2014 to January 1, 2017. Patients who were included and excluded in the analyses are summarized in the flow-chart in Fig. 1. Twenty-three patients were scheduled for surgery in the OR of the main hospital due to factors such as anticipated difficult airway or neuromuscular disorders. These 23 patients stayed overnight in the postanesthesia care unit. A total of 167 of the 798 patients who underwent surgery at the dental hospital had surgeries other than OMF and was excluded from the study group. Therefore, the present study included 631 patients who underwent OMF surgery under general anesthesia in the OR of the dental hospital. The characteristics of these patients are de- scribed in Table 1. Of our 631 patients, 131 patients $(20.8 \%)$ had cystic excision, 21 patients $(3.3 \%)$ underwent maxillomandibular fracture repair, 59 patients $(9.4 \%)$ were scheduled for iliac crest grafting for maxilla-mandibular reconstruction, 15 patients $(2.4 \%)$ underwent double-jaw surgery, and 405 patients $(64.2 \%)$ had other surgeries, including orthognathic surgery, implant surgery, osteotomy, plate removal, and abscess drainage.(Table 2)

Table 1. Patient characteristics $(n=631)$

\begin{tabular}{lc}
\hline \multicolumn{1}{c}{ Characteristic } & Value \\
\hline Age (yr) & $32.3 \pm 15.8$ \\
Sex (female/male) & $309 / 322(49.0 / 51.0)$ \\
Body weight $(\mathrm{kg})$ & $65.2 \pm 19.1$ \\
Mentally impaired patients & $15(2.4)$ \\
Patients with co-morbidity (ASA $<3)$ & $205(32.5)$ \\
Difficult airway (unanticipated) & $7(1.1)$ \\
Patients hospitalized after surgery & $174(27.6)$ \\
Overall recovery period duration (min) & $145.4 \pm 53.2$ \\
\hline
\end{tabular}

(ASA: American Society of Anesthesiology physical status score) Values are presented as mean \pm standard deviation or number $(\%)$. Filiz Uzumcugil et al: Overnight hospital stay and/or extended recovery period may allow long-duration oral and maxillofacial surgeries in the operating room of a dental hospital in an outpatient setting: a single-center experience.J Korean Assoc Oral Maxillofac Surg 2020

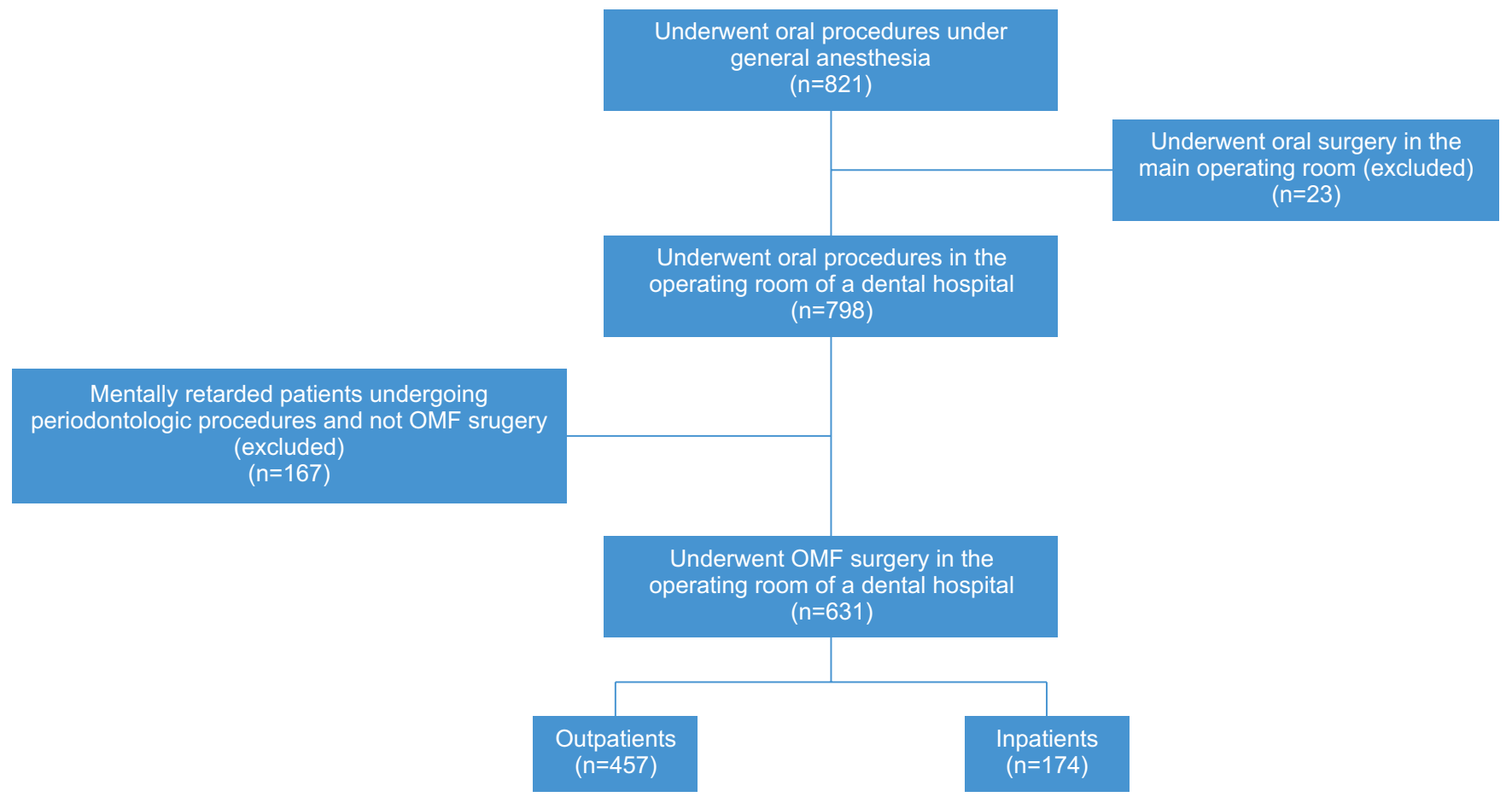

Fig. 1. Flow chart describing the number of patients reviewed, excluded, and analyzed. (OMF: oral and maxillofacial) Filiz Uzumcugil et al: Overnight hospital stay and/or extended recovery period may allow long-duration oral and maxillofacial surgeries in the operating room of a dental hospital in an outpatient setting: a single-center experience. J Korean Assoc Oral Maxillofac Surg 2020 


\section{Anesthetic management}

Patients were given midazolam preoperatively $(0.5 \mathrm{mg} /$ $\mathrm{kg}$; maximum $20 \mathrm{mg}$ peroral) as required. Anesthetic induction and maintenance were provided using sevoflurane (SEVORANE; Abbott Lab., Maidenhead, UK) or propofol (Propofol-Lipuro; B. Braun, Melsungen, Germany) according to patient needs. Short-acting rocuronium bromide (Curon; Mustafa Nevzat, Istanbul, Turkey) was used at an intravenous dose of $0.6 \mathrm{mg} / \mathrm{kg}$ for neuromuscular relaxation. The patients were endotracheally intubated via the nasal or oral pathway. Seven patients $(1.1 \%)$ had unanticipated difficult airway, but none of them required cancellation of the surgery. Shortacting remifentanil (Ultiva; GlaxoSmithKline Manufacturing S.p.A, Parma, Italy) infusion was used for analgesia during surgery. None of the patients received nitrous oxide $\left(\mathrm{N}_{2} \mathrm{O}\right)$ during the procedures. All patients were given $1 \mathrm{mg} / \mathrm{kg}$ intravenous methylprednisolone (Prednol-L; Mustafa Nevzat) to prevent edema formation and ondansetron $(0.1 \mathrm{mg} / \mathrm{kg})(\mathrm{Ke}-$ moset; DEVA-EastPharma, Istanbul, Turkey) to prevent postoperative nausea and vomiting (PONV). All patients received intravenous acetaminophen (Paracerol; AROMA, Tekirdag, Turkey) and tenoxicam (Tilcotil; DEVA-EastPharma) for pain control 15 to 30 minutes prior to the end of surgery.

\section{Outcome parameters}

There was no significant difference in number of patients with comorbidities between the outpatient and hospitalized patient groups $(P=0.389)$.(Table 3$)$ The duration of surgery was significantly longer in hospitalized patients $(P<0.001)$. (Table 3) The duration of surgery was longest in the doublejaw surgery patients, but there was no significant difference in length compared to the iliac crest grafting surgery length. (Table 2) The outpatient and hospitalized patient groups had no significant difference in terms of duration of surgery in these long-duration procedures.(Table 3, Fig. 2)

Postoperative adverse events are described in Table 4. None of these events required hospitalization. Eight of the hospitalized patients (4.6\%) developed adverse events other than pain, but hospitalization was not the cause of any of these events. Most ( $\mathrm{n}=165,80 \%)$ patients who developed these adverse events required therapeutic intervention.(Table

Table 3. The relationships between hospitalization rate, presence of co-morbidities, and duration of surgery

\begin{tabular}{lccr}
\hline & $\begin{array}{c}\text { Outpatient } \\
(\mathrm{n}=457)\end{array}$ & $\begin{array}{c}\text { Inpatient } \\
(\mathrm{n}=174)\end{array}$ & $P$-value \\
\hline $\begin{array}{c}\text { The presence of } \\
\text { co-morbidities }\end{array}$ & & & 0.389 \\
$\quad$ With co-morbidities & $304(66.5)$ & $122(70.1)$ & \\
$\quad$ Without co-morbidities & $153(33.5)$ & $52(29.9)$ & \\
Duration of surgery (min) & $105.25 \pm 57.48$ & $189.62 \pm 82.03$ & $<0.001 *$ \\
\hline
\end{tabular}

$* P<0.05$.

Values are presented as number (\%) or mean \pm standard deviation. Filiz Uzumcugil et al: Overnight hospital stay and/or extended recovery period may allow long-duration oral and maxillofacial surgeries in the operating room of a dental hospital in an outpatient setting: a single-center experience. J Korean Assoc Oral Maxillofac Surg 2020

Table 2. The relationship between outpatient and hospitalized patients in terms of durations of types of surgeries

\begin{tabular}{|c|c|c|c|c|c|}
\hline Surgical type & Hospitalization & No. of patients & Mean \pm SD (min) & Mean difference \pm SD $(\min )$ & $P$-value \\
\hline \multirow[t]{3}{*}{ Cyst excision } & Total & 131 & $94.65 \pm 36.08$ & & \\
\hline & No & 109 & $88.76 \pm 31.49$ & $35.10 \pm 7.88$ & $<0.001 *$ \\
\hline & Yes & 22 & $123.86 \pm 43.45$ & & \\
\hline \multirow[t]{3}{*}{ Fracture } & Total & 21 & $127.62 \pm 49.99$ & & \\
\hline & No & 8 & $111.87 \pm 28.27$ & $25.43 \pm 22.29$ & 0.268 \\
\hline & Yes & 13 & $137.31 \pm 58.58$ & & \\
\hline \multirow[t]{3}{*}{ Double-jaw } & Total & 15 & $310.00 \pm 54.21$ & & \\
\hline & No & 4 & $266.25 \pm 77.82$ & $59.65 \pm 28.37$ & 0.056 \\
\hline & Yes & 11 & $325.91 \pm 35.41$ & & \\
\hline \multirow[t]{3}{*}{ Iliac graft } & Total & 59 & $211.86 \pm 61.02$ & & \\
\hline & No & 12 & $194.17 \pm 40.77$ & $22.21 \pm 19.69$ & 0.264 \\
\hline & Yes & 47 & $216.38 \pm 64.77$ & & \\
\hline \multirow[t]{3}{*}{ Other } & Total & 405 & $120.65 \pm 70.58$ & & \\
\hline & No & 324 & $105.35 \pm 59.12$ & $76.49 \pm 7.90$ & $<0.001^{*}$ \\
\hline & Yes & 81 & $181.85 \pm 79.39$ & & \\
\hline \multirow[t]{3}{*}{ Total } & Total & 631 & $128.51 \pm 75.26$ & & \\
\hline & No & 457 & $105.25 \pm 57.48$ & $43.78 \pm 9.77$ & $<0.001 *$ \\
\hline & Yes & 174 & $189.62 \pm 82.03$ & & \\
\hline
\end{tabular}

(SD: standard deviation)

$* P<0.05$.

Filiz Uzumcugil et al: Overnight hospital stay and/or extended recovery period may allow long-duration oral and maxillofacial surgeries in the operating room of a dental hospital in an outpatient setting: a single-center experience. J Korean Assoc Oral Maxillofac Surg 2020 


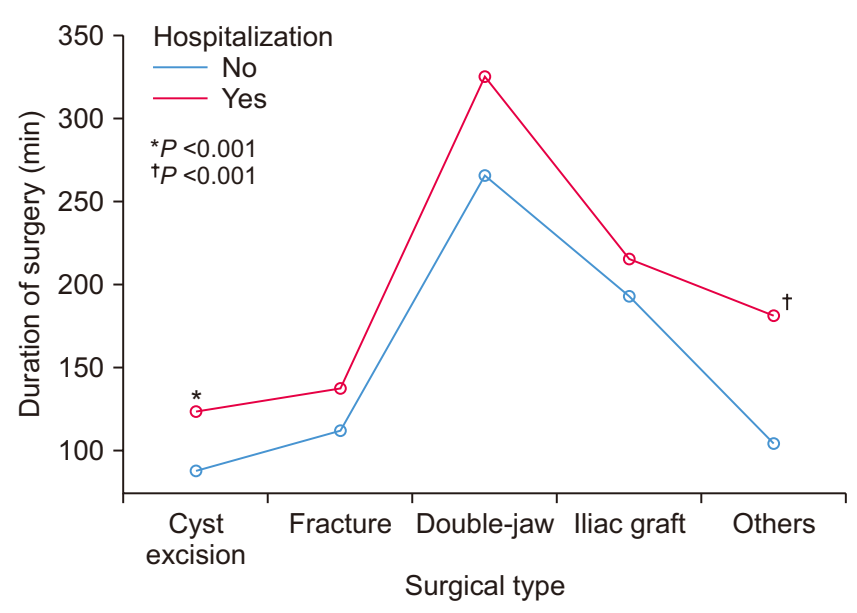

Fig. 2. Surgical duration in outpatient and inpatient cases according to type of surgery.

Filiz Uzumcugil et al: Overnight hospital stay and/or extended recovery period may allow long-duration oral and maxillofacial surgeries in the operating room of a dental hospital in an outpatient setting: a single-center experience.J Korean Assoc Oral Maxillofac Surg 2020

4) Only 1 patient required unanticipated hospital admission due to unexpectedly long duration of surgery. None of the patients required re-admission after 24-hour follow-up and discharge.

The overall recovery period was significantly longer in outpatient compared to hospitalized patients.(Table 5, Fig. 3) All patients fulfilled the discharge criteria (score $\geq 9$ ) as measured by the MAS.

\section{Discussion}

Our results showed that duration of surgery significantly affected need for overnight hospital stay following OMF surgery performed in the OR of a dental hospital with an outpatient setting. Preoperative evaluations that included consideration for an overnight hospital stay prevented unanticipated admissions and patient re-admission after discharge. The opportunity to extend the recovery period postoperatively and/or schedule a planned overnight hospital stay allowed OMF surgeries longer than 90 minutes to be performed in the OR of an outpatient facility regardless of the type of surgery planned.

The guidelines recommended by the American Association of Oral and Maxillofacial Surgeons (AAOMS) and the American Dental Association (ADA) suggest hospital-based surgeries for patients who are scheduled for complex surgeries and who are in need of comprehensive hospital or intensive care unit (ICU) monitoring during the postoperative period ${ }^{1}$. However, the characteristics of patients who require complex
Table 4. Postoperative adverse events after oral and maxillofacial surgery

\begin{tabular}{lrcc}
\hline \multicolumn{1}{c}{$\begin{array}{c}\text { Postoperative } \\
\text { adverse event }\end{array}$} & $\mathrm{n}(\%)$ & Outpatient & Inpatient \\
\hline Bradycardia/arrhythmia & $5(0.8)$ & 4 & 1 \\
Hypotension & $6(1.0)$ & 3 & 3 \\
Hypertension & $11(1.7)$ & 6 & 5 \\
Spasm & $8(1.3)$ & 6 & 2 \\
Stridor & $8(1.3)$ & 5 & 3 \\
Respiratory depression & $2(0.3)$ & 1 & 1 \\
Nausea/vomiting & $36(5.7)$ & 23 & 13 \\
Bleeding & $1(0.2)$ & 1 & 0 \\
Pain & $128(20.3)$ & 81 & 47 \\
Total & $205(32.5)$ & 130 & 75 \\
Requiring medication for & $165(26.1)$ & 98 & 67 \\
$\quad$ any adverse event & & & \\
Total No. of patients & 631 & 457 & 174 \\
\hline
\end{tabular}

Filiz Uzumcugil et al: Overnight hospital stay and/or extended recovery period may allow long-duration oral and maxillofacial surgeries in the operating room of a dental hospital in an outpatient setting: a single-center experience. J Korean Assoc Oral Maxillofac Surg 2020

surgery and hospital or ICU admission may vary. Therefore, these patients should be assessed individually. The anesthesia team at our hospital performs a triage process to classify patients scheduled for OMF surgery. Patients with ASA physical status score $\geq 3$, difficult airway, or potential risks for adverse events due to either anesthesia or surgery are scheduled in the OR at the main hospital in an inpatient setting, while patients with ASA physical status score $<3$ regardless of the surgery's anticipated duration are scheduled for the OR at the Faculty of Dentistry, an outpatient setting; overnight hospital stay is only planned if needed. Verco et al. ${ }^{3}$ investigated the clinical incidents that necessitated transfer to a hospital for an inpatient stay after OMF surgery. The dental hospital in which they performed their surgeries was an outpatient setting without any facilities for an overnight stay, similar to our hospital setting. These authors highlighted the importance of patient selection to decrease the incidence of adverse events. However, despite the use of stringent selection criteria, unanticipated events occurred in some patients $(0.13 \%)$ that required transfer to another hospital for inpatient stay ${ }^{3}$. In contrast, Jastak and Peskin ${ }^{6}$ reported 13 cases of morbidities; 10 of these were considered avoidable had proper patient selection criteria or timely recognition and treatment of adverse events occurred. The triage process carried out in our hospital to determine the location of the surgeries and the need for overnight stay prevented unanticipated admissions.

\section{Decision to schedule overnight hospital stay}

Overnight hospital stay is recommended for patients whose 
Table 5. Overall recovery period of long-duration surgeries and other types of surgeries between outpatient and inpatient groups

\begin{tabular}{lcccr}
\hline \multirow{2}{*}{ Surgical type $(\mathrm{n})$} & \multicolumn{3}{c}{ Overall recovery period $(\mathrm{min})$} & \multirow{2}{*}{$P$-value } \\
\cline { 2 - 4 } & Inpatient & Outpatient & Mean difference & \\
\hline Double-jaw $(\mathrm{n}=15)$ & $95.45 \pm 29.78$ & $165.0 \pm 21.21$ & $69.54 \pm 16.37$ & $0.001^{*}$ \\
Iliac graft $(\mathrm{n}=59)$ & $126.49 \pm 24.56$ & $181.25 \pm 65.89$ & $54.76 \pm 11.77$ & $<0.001^{*}$ \\
Other $(\mathrm{n}=557)$ & $118.79 \pm 47.0$ & $148.84 \pm 51.62$ & $30.04 \pm 5.29$ & $<0.001^{*}$ \\
Total $(\mathrm{n}=631)$ & $119.40 \pm 41.60$ & $149.83 \pm 52.04$ & $30.43 \pm 21.79$ & $<0.001^{*}$ \\
\hline
\end{tabular}

$* P<0.05$

Values are presented as mean \pm standard deviation.

Filiz Uzumcugil et al: Overnight hospital stay and/or extended recovery period may allow long-duration oral and maxillofacial surgeries in the operating room of a dental hospital in an outpatient setting: a single-center experience. J Korean Assoc Oral Maxillofac Surg 2020

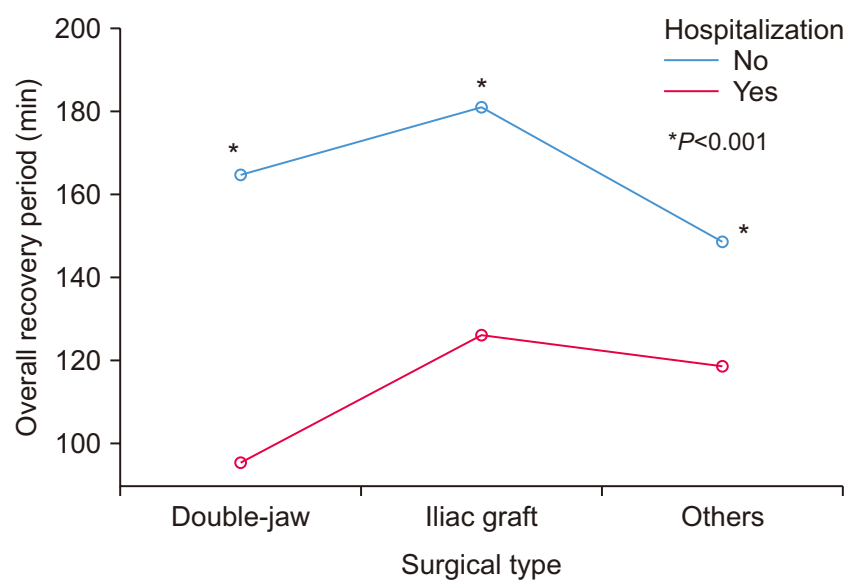

Fig. 3. Overall recovery period of long-duration surgeries and other types of surgeries between outpatient and inpatient groups. Filiz Uzumcugil et al: Overnight hospital stay and/or extended recovery period may allow long-duration oral and maxillofacial surgeries in the operating room of a dental hospital in an outpatient setting: a single-center experience. J Korean Assoc Oral Maxillofac Surg 2020

ASA physical status score is $\geq 3$ and/or whose surgery is predicted to last $>90$ minutes $^{4}$. The results of our study revealed that duration of surgery was the main predictor for hospital stay for patients with ASA score $<3(P<0.001)$. However, our hospitalized patient group comprised surgeries that lasted $<90$ minutes, whereas the outpatient group contained surgeries that lasted $>90$ minutes. Therefore, duration of surgery was the primary but not the only factor that determined need for hospital stay in our study. The recovery period immediately after the procedure was extended (145.4 \pm 53.2 minutes) when necessary for any of our patients. An extended recovery period allowed us to schedule longer surgeries regardless of type in an outpatient setting without the need for a hospital stay. Cortiñas-Saenz et al. ${ }^{8}$ examined disabled patients undergoing oral ambulatory surgeries. They provided an extended recovery period (140.91 \pm 29.78 minutes) similar to our study but reported an unplanned hospital admission rate of $1.92 \%{ }^{8}$. Therefore, an extended recovery period does not necessarily prevent hospitalization, and some patients will require a planned hospital stay in addition to the extended recovery period. The extended recovery period and planned overnight hospital stay in our study prevented the unplanned admissions due to avoidable or predictable adverse events. However, it is clear that an overnight hospital stay would likely be necessary for surgeries $>90$ minutes in length if this recovery period cannot be extended at the request of the anesthesiologist and the surgeon.

\section{Types of surgeries}

In our study, the hospitalization rates were $79 \%, 73 \%$, and $61.9 \%$ in patients undergoing iliac crest grafting, double-jaw surgery, and fracture repair, respectively. In these surgeries with high hospitalization rates, the duration of the procedures had no significant difference between outpatient and hospitalized patients.(Table 2) It should be highlighted that despite the long-duration of double-jaw and iliac crest grafting surgeries, some patients were discharged without hospital stay. The extended recovery period allowed long-duration surgeries to be performed without hospitalization.(Table 5)

\section{Decision for discharge}

The guidelines of the AAOMS and ADA suggest use of standard discharge criteria ${ }^{9}$. The anesthesiologist and the surgeon at our hospital jointly made the discharge decision. The anesthesiologist used the standard discharge criteria of the MAS, where a score $\geq 9$ indicates that the patient can be discharged ${ }^{7}$. Both groups of patients fulfilled the discharge criteria. Patients who were discharged to home $(n=457,72.4 \%)$ or transferred to the main hospital ( $\mathrm{n}=174,27.6 \%)$ by ambulance also met the discharge criteria. Our patients' monitored recovery period (145 \pm 53.2 minutes [range, 40-570 minutes]) was extended until they met the criteria. The status of the patients for bleeding, PONV, and pain was also considered as part of the discharge criteria. Bleeding, PONV, and pain occurred in $0.2 \%(n=1), 5.7 \%(n=36)$, and $20.3 \%(n=128)$ 
of our patients, respectively. None of these adverse effects required hospitalization. These patients were monitored until these events resolved prior to discharge or transfer to the main hospital. None of the patients required re-admission after discharge.

\section{Adverse events in the intraoperative and postoperative periods}

The major problem in the intraoperative period was unanticipated difficult airway. Seven of the 631 patients (1.1\%) had unanticipated difficult airway, but none required discontinuation of anesthesia. All these patients were endotracheally intubated at the start of the procedure and extubated in the OR without complication.

Previous studies that have addressed bleeding after oral surgery have most commonly focused on use of anticoagulants ${ }^{10,11}$. These studies reported a $2 \%{ }^{10}$ and $1.2 \%{ }^{11}$ rate of bleeding after oral surgery in healthy patients who did not use any anticoagulant or antiplatelet agents, respectively. A metaanalysis of observational studies reported a bleeding risk of $1.1 \%$ in patients who did not use anticoagulants ${ }^{12}$. Bleeding occurred in only one patient $(0.2 \%)$ in our study, which is a lower rate than that in the currently available data. The reason for our low result may be the retrospective nature of our study because only patients who needed an intervention were recorded. Bleeding immediately after surgery that was controlled via compression with gauze was not recorded.

The overall incidence of PONV was reported as $20 \%$ to $30 \%$ after OMF surgeries ${ }^{13}$. Rastogi et al. ${ }^{14}$ found the incidence of PONV after surgeries for mandibular fractures and temporomandibular joint ankylosis under general anesthesia to be $32 \%$. Our study revealed an incidence of $5.7 \%$ PONV, which is lower than the currently available data. All our patients received ondansetron at the end of the procedure as a prophylactic measure, and none of our patients received $\mathrm{N}_{2} \mathrm{O}$ during the intraoperative period. They all were given the short-acting opioid remifentanil as an infusion for analgesia during surgery instead of $\mathrm{N}_{2} \mathrm{O}$. Our standard prophylactic and preventive measures may have led to the low incidence of PONV in our study.

Pain is one of the most important adverse effects after OMF surgery, and it has been addressed in many studies. Preventive, pre-emptive, and therapeutic management strategies are used to decrease the incidence and severity of pain after surgery. All patients in our study group received paracetamol and tenoxicam intravenously during the intraoperative pe- riod. Rescue medication was provided as diclofenac sodium intramuscularly (119 patients) or morphine (2 patients) or pethidine $\mathrm{HCl}$ (12 patients) intravenously in the recovery room. Oral nonsteroidal anti-inflammatory drugs were also prescribed for all patients except where contraindicated. The incidence of pain was $20.3 \%$, and none of our patients required hospitalization due to refractory pain.

\section{Conclusion}

The results of our study suggest that, regardless of type, longer OMF surgeries may be performed in the OR of an outpatient facility if an extended recovery period and/or an overnight hospital stay is also available. A triage process performed by an experienced anesthesia team prior to surgery may offer a safer approach by dispatching patients to the OR of an outpatient or inpatient setting either with or without a hospital stay.

\section{ORCID}

Filiz Uzumcugil, https://orcid.org/0000-0001-9161-3248

Aysun Ankay Yilbas, https://orcid.org/0000-0001-6196-3191

Basak Akca, https://orcid.org/0000-0003-4069-2462

Demet Basak Ozkaragoz, https://orcid.org/0000-0002-4754-6348

Selen Adiloğlu, https://orcid.org/0000-0002-5007-9867

Hıfzı Hakan Tuz, https://orcid.org/0000-0002-3883-2406

Meral Kanbak, https://orcid.org/0000-0002-1727-2032

\section{Authors' Contributions}

F.U., A.A.Y., B.A., D.B.O., and S.A. participated in data collection and study design. F.U. and H.H.T. wrote the manuscript. F.U. and M.K. participated in study design and coordination and M.K. helped the draft the manuscript. All authors read and approved the final manuscript.

\section{Ethics Approval and Consent to Participate}

This study was obtained approval from the Institutional Ethical Committee (GO17/83-21, 28.02.2017) of Hacettepe University, and the informed consent was waived.

\section{Conflict of Interest}

No potential conflict of interest relevant to this article was reported. 


\section{References}

1. Stronczek MJ. Determining the appropriate oral surgery anesthesia modality, setting, and team. Oral Maxillofac Surg Clin North Am 2013;25:357-66, v.

2. Lieblich S. Preoperative evaluation and patient selection for officebased oral surgery anesthesia. Oral Maxillofac Surg Clin North Am 2018;30:137-44.

3. Verco S, Bajurnow A, Grubor D, Chandu A. A five-year assessment of clinical incidents requiring transfer in a dental hospital day surgery unit. Aust Dent J 2011;56:412-6.

4. Özkan AS, Erdoğan MA, Şanlı M, Kaçmaz O, Durmuş M, Çolak C. Retrospective evaluation of dental treatment under general anaesthesia. Turk J Anaesthesiol Reanim 2015;43:332-6.

5. Whippey A, Kostandoff G, Paul J, Ma J, Thabane L, Ma HK. Predictors of unanticipated admission following ambulatory surgery: a retrospective case-control study. Can J Anaesth 2013;60:675-83.

6. Jastak JT, Peskin RM. Major morbidity or mortality from office anesthetic procedures: a closed-claim analysis of 13 cases. Anesth Prog 1991;38:39-44.

7. Aldrete JA. The post-anesthesia recovery score revisited. J Clin Anesth 1995;7:89-91.

8. Cortiñas-Saenz M, Martínez-Gómez L, Roncero-Goig M, SaezCuesta U, Ibarra-Martin M. Results of a major ambulatory oral surgery program using general inhalational anesthesia on disabled patients. Med Oral Patol Oral Cir Bucal 2009;14:e605-11.

9. Kramer KJ. Discharge criteria, impact of the patient and the procedure: what the oral surgeon should know. Oral Maxillofac Surg Clin North Am 2017;29:197-208.
10. Broekema FI, van Minnen B, Jansma J, Bos RR. Risk of bleeding after dentoalveolar surgery in patients taking anticoagulants. Br J Oral Maxillofac Surg 2014;52:e15-9.

11. Bajkin BV, Vujkov SB, Milekic BR, Vuckovic BA. Risk factors for bleeding after oral surgery in patients who continued using oral anticoagulant therapy. J Am Dent Assoc 2015;146:375-81.

12. Shi Q, Xu J, Zhang T, Zhang B, Liu H. Post-operative bleeding risk in dental surgery for patients on oral anticoagulant therapy: a metaanalysis of observational studies. Front Pharmacol 2017;8:58.

13. Cruthirds D, Sims PJ, Louis PJ. Review and recommendations for the prevention, management, and treatment of postoperative and postdischarge nausea and vomiting. Oral Surg Oral Med Oral Pathol Oral Radiol 2013;115:601-11.

14. Rastogi A, Gyanesh P, Nisha S, Agarwal A, Mishra P, Tiwari AK. Comparison of general anaesthesia versus regional anaesthesia with sedation in selected maxillofacial surgery: a randomized controlled trial. J Craniomaxillofac Surg 2014;42:250-4.

How to cite this article: Uzumcugil F, Ankay Yilbas A, Akca B, Ozkaragoz DB, Adiloğlu S, Tuz HH, et al. Overnight hospital stay and/or extended recovery period may allow long-duration oral and maxillofacial surgeries in the operating room of a dental hospital in an outpatient setting: a single-center experience. J Korean Assoc Oral Maxillofac Surg 2020;46:125-132. https://doi.org/10.5125/ jkaoms.2020.46.2.125 